\title{
A parassinonímia em atlas linguísticos regionais brasileiros
}

\author{
Maria do Socorro Silva de ARAGÃo *
}

Resumo: Este trabalho procura buscar, na literatura especializada, resposta à questão: os itens lexicais dos Atlas Linguísticos constituem parassinônimos? Após a leitura de vários autores das áreas de semântica, semiótica, lexicologia e lexicografia, com diferentes visões sobre o tema, chegamos à conclusão, concordando com esses autores, de que a questão da sinonímia é uma questão de gradação e de variação quer linguística, quer extralinguística, e que não há sinônimo perfeito, uma vez que o semema de nenhum item lexical recobre totalmente o semema de outro item. Como corpus para essa análise utilizamos cinco dos Atlas Linguísticos Regionais do Brasil, publicados: Bahia, Minas Gerais, Paraíba, Sergipe e Paraná. Para nossa análise trabalhamos com itens lexicais de algumas cartas léxicas dos campos semânticos "fenômenos atmosféricos", "o corpo humano" e "cultura e convívio", dos cinco Atlas brasileiros publicados. Respondendo à questão inicial, se os itens lexicais dos Atlas Linguísticos são parassinônimos, estamos seguros que sim, que cada um deles, apesar de terem os mesmos semas genéricos, seus semas específicos e virtuais recobrem realidades geográficas regionais diferentes, que se constituem em subsistemas marcados pela variação diatópica, já que diastraticamente as marcas da variação social: faixa etária, sexo e

\footnotetext{
* Doutora em Linguística pela Universidade de São Paulo (1974); pósdoutorado pela Université de Paris III (Sorbonne-Nouvelle) (1977); pósdoutorado pela Universidad Complutense de Madrid (1978) e pósdoutorado pela Central Connecticut State University (1990). Docente da Universidade Federal do Ceará e da Universidade Federal da Paraíba. Contato: socorro.aragao@terra.com.br.
} 
nível de escolarização, têm características semelhantes ou iguais, o que contraria a visão de alguns autores da área.

Palavras-chave: Parassinônimos; Itens lexicais; Atlas linguísticos.

Abstract: This work tries to find, in the specialized literature, the answer to the question: the lexical items of the Linguistic Atlas constitute parasinonims? After reading various authors of the areas of semantics, semiotics, lexicology and lexicography, with different visions of the theme, we came to the conclusion, agreeing with these authors, that the question of synonyms is a question of grade and variation that could be linguistical or extralinguistical, and that there is no perfect synonym, once the sememe of any lexical item totally covers the sememe of the other item. As the corpus for the analysis we used five Linguistic Regional Atlas of Brazil: Bahia, Minas Gerais, Paraíba, Sergipe and Paraná. For this analysis we worked with lexical items of some lexical maps of the semantic field "atmospherically phenomena", the "human body" and "culture and living", of the five Brazilian published Atlas. Answering to the initial question, if the lexical items of the Linguistics Atlas are parasinonims, we are sure that each one of them, even having the same generic semes, its specific and virtual semes cover different geographical regional realities, that constitute a subsystem marked by the diatopic variation, since diastratic the marks of the social variation: age, gender and school level, have same of similar characteristics, what goes against the vision of some authors in the area.

Keywords: Parasynonims; Lexical items; Linguistic atlas.

\section{Introdução}

Os estudiosos da semântica, desde tempos imemoriais, têm dado destaque particular ao problema da sinonímia e, a partir desses estudos, questões as mais diversas são levantadas sobre a existência ou não de sinônimos. Se eles existem, como são definidos, como funcionam, qual o seu status, em termos cognitivos e/ou afetivos, 
se eles são absolutos ou parciais, se estão limitados à denotação ou se ligados à conotação em cada contexto particular.

É a partir desses questionamentos e discussões que surge a noção de parassinônimos, quase sinônimos, sinônimos parciais e sinônimos em discurso, para designar "termos de mesmo sentido, porém onde as distribuições não são exatamente equivalentes", no dizer de Galisson e Coste (1976, p. 399).

Nosso trabalho procurará buscar, na literatura especializada, resposta à questão: os itens lexicais dos Atlas Linguísticos constituem parassinônimos?

Como corpus para esta análise utilizamos os Atlas Linguísticos Regionais do Brasil, publicados até a presente data: Bahia, Minas Gerais, Paraíba, Sergipe e Paraná.

\section{As unidades lexicais e sua significação}

Embora o estudo dos sinônimos e, consequentemente, dos parassinônimos, esteja ligado ao significado e logo, à semântica, a abordagem primeira, básica, tem que ser do léxico, da lexicologia e da lexicografia e, posteriormente, da sintaxe da frase ou enunciado.

Ullmann $(1964$, p. 298) chega a dizer que "as distinções entre sinônimos são um grande desafio ao engenho do lexicógrafo".

Tal afirmação é confirmada por Barbosa (1998, p. 19-20) no seguinte excerto:

Em qualquer das fases metodológicas de elaboração da macroestrutura, da microestrutura e dos processos de remissivas de uma obra lexicográfica e/ou terminológica, a aplicação das relações de significação, ou seja, das relações que se estabelecem entre o plano do conteúdo e o plano da expressão das unidades lexicais, é de fundamental importância.

Os tipos de relações de sentido existentes entre itens lexicais são determinados pela função dessas relações. Assim, o significado é uma função das relações de significado, como defende Lyons (1974, p. 101). 
Ao comentar as relações sinonímicas de sentido, Lopes (1976, p. 255) afirma que "[...] o sentido dos elementos lingǘsticos é um sentido relacional e é uma consequência derivada do caráter estrutural dos signos [...]". Complementa o pensamento afirmando que "[...] a sino (nímia) não é, contrariamente ao que se crê, uma propriedade das palavras em si, mas é, isto sim, uma propriedade estrutural do código, ou melhor, das relações que instauram as estruturas" (LOPES, 1976, p. 256).

Ao tratar das relações de significação dos itens lexicais, Cruse (1991, p. 1) afirma que as propriedades semânticas de um item lexical são plenamente refletidas nos aspectos das relações que mantêm com contextos atuais e potenciais. Para o autor, o significado de uma palavra é constituído por suas relações contextuais. Em suas palavras: "[...] the meaning of a word is constituted by its contextual relations" e encerra seu pensamento asseverando que a unidade lexical é a união de uma forma lexical e um sentido único.

O mesmo autor dissertando, ainda, sobre as propriedade semânticas de um item lexical confirma que "[...] The semantic properties of a lexical item are fully reflected in appropriate aspects of the relations it contracts with actual and potential contexts."

Assim, as relações e o contexto real ou potencial do item lexical é que determinarão seu conteúdo semântico.

Para Cruse (1991) há dois tipos básicos de relações de significação do item lexical: as relações paradigmáticas e as relações sintagmáticas. Afirma que as relações paradigmáticas representam sistemas de escolha que o falante faz quando codifica suas mensagens, acrescentando, ainda, que:

Paradigmatic relations, for the most part, reflect the way infinitely and continuous varied experienced reality is apprehended and controlled through being categorized, subcategorized and graded along specific dimensions of variation. (CRUSE, 1991, p. 86) 
Já as relações sintagmáticas servem para dar coesão à mensagem, acrescentando-lhe redundância informacional. Em suas palavras:

Sintagmatic aspect of lexical meaning, on the other hand, serve discourse cohesion, adding necessary informational redundancy to the message, at the same time controlling the semantic contribution of individual utterance elements through disambiguation, for instance, or by signaling alternative - e.g. figurative - strategies of interpretation. (CRUSE, 1991, p. 86)

\section{Sinonímia e parassinonímia}

As diferentes definições e delimitações da sinonímia partem de princípios e bases diversas, razão por que, dependendo do ponto de que se parte, essas definições ora se opõem, ora se complementam.

Para Crystal (1988, p. 453), a sinonímia é “o termo usado na semântica com referência a um importante tipo de relação de sentido entre os itens lexicais: os itens lexicais que têm a mesma significação são sinônimos - estão em relação de sinonímia".

Lyons (1979) concorda com Crystal quando reitera que a sinonímia é uma relação de sentido, mostrando que, neste caso, não é uma questão de referência, "visto que a identidade de significado - a sinonímia - é uma relação que se estabelece entre duas ou mais unidades vocabulares, é uma questão de sentido e não de referência". Acrescenta, ainda, que a "sinonímia é estabelecida entre unidades lexicais e não entre sentidos" (LYONS, 1979, p. 453).

Alguns autores ligam a sinonímia ao aspecto cognitivo, afetivo ou denotativo e outros ao conotativo. Dependendo dessas visões podem surgir controvérsias, uma vez que o sentido poderia ficar à mercê de aspectos subjetivos do emissor/receptor, o que seria por demais difícil para o lexicógrafo, por exemplo, elaborar suas definições e remissões. 
Ao tratar da sinonímia cognitiva, Cruse (1991, p. 270) a define como "um par de itens lexicais que tenham certas propriedades semânticas em comum". Concorda o autor que são poucos os pares dos chamados sinônimos absolutos, uma vez que eles, de alguma forma, terão alguma diferença de sentido: “[...] very few pairs of cognitive synonyms are absolute synonyms $[\ldots]$ in the majority of cases a lexical item must, in some respects at least, be different in meaning from any of its cognitive synonyms (CRUSE, 1991, p. 270).

Ainda tratando do sinônimo absoluto, Cruse (1991, p. 277) afirma que há uma grande distinção entre os dois modos de manifestação dos itens lexicais. Para ele, os dois modos de manifestação dos itens lexicais são: o modo proposicional e o modo expressivo.

O modo proposicional depende da atitude proposicional expressa na frase na qual opera o item, ou seja, se é uma afirmação, interrogação, comando ou exclamação, por exemplo.

No modo expressivo o significado do item lexical não determina uma condição verdadeira, mas pode reforçar a intensidade de determinado sentido.

Assim, o significado inerente de um item lexical pode ser construído de um ou de ambos os tipos de significado. Se dois itens lexicais são sinônimos cognitivos, então, serão idênticos nos traços proposicionais, mas podem diferir nos traços expressivos.

Complementando sua visão de sinônimo absoluto, Cruse (1991, p. 290) concorda que ele não é natural e é instável. Em suas palavras: "Absolute synonymy was shown to be a somewhat rare phenomenon, but whereas there is reason to believe that absolute synonymy is in some sense unnatural, and very probably unstable..."

Matthews (1997, p. 367), ao definir sinonímia, mostra que “[...] relação entre duas unidades lexicais com um sentido compartido - sinônimo absoluto, se eles existem, têm significado idêntico em todos os aspectos e em todos os contextos".

A questão, e a discussão a partir dela, é se há sinônimos e se eles são ou podem ser absolutos ou não, surgindo a partir daí a 
noção de parassinônimo e suas demais denominações: sinônimo parcial, quase sinônimo, sinônimo incompleto, sinônimo de discurso e pseudossinônimo.

A certeza que todos têm atualmente é a de que não há sinônimos perfeitos nem absolutos, uma vez que os sememas de dois itens lexicais não recobrem totalmente um ao outro, ou seja, os semas genéricos, específicos e virtuais não podem ser totalmente iguais. Haverá sempre, pelo menos, um sema diferente. Para Matthews (1997, p. 178), o que existe são sinônimos parciais que: "[...] têm sentido idêntico em alguns contextos, ou idêntico apenas ao substituir outro que não muda as condições de verdade de uma sentença".

Outro aspecto importante envolvido na discussão de sinonímia - parassinonímia - é a noção de contexto, que pode ser linguístico, mas, também, extralinguístico, como o espacial ou geográfico, o temporal, o situacional ou o técnico, por exemplo, em que a similaridade de dois itens lexicais pode ocorrer num desses e não se realizar em outros. Barbosa (1998, p. 31) mostra que "são casos de parassinonímia as paráfrases culturais, as diferentes 'visões' para o mesmo esquema conceptual, as variantes diacrônicas, diatópicas, diastráticas e diafásicas".

Para Cruse (1991, p. 282-283), a variação geográfica não tem muita significação para os sinônimos ou parassinônimos, mas a variação social é de primordial importância, fato que não foi confirmado em nosso corpus.

Xavier e Mateus (1992, p. 288) definem parassinônimos como os “[...] termos que têm o mesmo significado, mas não têm distribuições exactamente equivalentes, i.e., que não são comutáveis em todos os contextos".

Galisson e Coste (1976, p. 399) acrescentam a isto o conceito de uso, emprego, registro e domínio da experiência, para fechar o conceito de parassinônimo: "Por vezes, o desvio distribucional não é devido à especialização em domínios da experiência diversa, mas observa-se em registros de discurso diferente".

Finalmente, uma visão da parassinonímia em termos de relações de conjunto significante e conjunto significado nos dá 
Barbosa (1998, p. 21), ao afirmar que ela ocorre quando "[...] a dois ou mais elementos do conjunto significante, em relação de oposição disjuntiva, correspondem dois ou mais elementos do conjunto significado, estes em relação de oposição transitiva".

\section{Os itens lexicais dos atlas linguísticos e sua relação de significação}

Uma das bases da Geografia Linguística é o estudo das variações diatópicas, ou geográficas, no nível do léxico. É nessas variações, como também nas fonéticas, onde se encontram as marcas delimitadoras dos falares regionais.

A afinidade de significados, como afirma Pottier (1974; 1987), que é encontrada na parassinonímia, pode situar o falante em diferentes subsistemas como o espacial, o temporal, o situacional ou de tecnicidade.

Para nosso objetivo trabalharemos em termos de contexto espacial.

\subsection{Os atlas linguisticos regionais do Brasil}

O Brasil já possui, até o momento, dezessete Atlas Linguísticos realizados, dos quais nove publicados. Os Atlas Linguísticos estaduais brasileiros publicados são: o Atlas Prévio dos Falares Baianos (1963), o Esboço de um Atlas Lingüistico de Minas Gerais (1977), o Atlas Lingüistico da Paraíba (1984), o Atlas Lingüístico de Sergipe (1987), o Atlas Lingüistico do Paraná (1994), o Atlas Lingüistico de Sergipe II (2002) e o Atlas Lingüistico Sonoro do Estado do Pará (2004) e o Atlas Lingüistico de Mato Grosso do Sul (2007). O Attas Lingüistico Etnográfico da Região Sul (2002) é o único Atlas Regional brasileiro. Os oito últimos Atlas elaborados, mas ainda não publicados, são: Atlas Lingüistico do Ceará; Atlas Lingüistico do Amazonas, tese defendida na UFRJ em 2004; Atlas Fonético do entorno da Baía da Guanabara, dissertação defendida na UFRJ em 2006; Atlas Lingüistico do município de Ponta Porã-MS: um registro das linguas em contato na fronteira do Brasil com o Paraguai, dissertação defendida 
na UFMS em 2006; Atlas Lingüístico do Paraná II, tese defendida na UEL em 2007; Atlas geolingüistico do litoral Potiguar, tese defendida na UFRJ em 2007; Micro Atlas Fonético do Estado do Rio de Janeiro, tese defendida na UFRJ em 2008; Atlas Linguistico da mesorregião Sudeste de Mato Grosso, dissertação defendida na UFMS em 2009.

Outros tantos Atlas estaduais encontram-se em fase avançada ou inicial de elaboração, como o Atlas Linguístico Sonoro do Estado do Rio de Janeiro; o Atlas Linguístico de São Paulo; o Atlas Linguístico do Acre; o Atlas Linguístico do Mato Grosso; o Atlas Linguístico do Espírito Santo; o Atlas Geo-Sociolinguístico do Pará; o Atlas Linguístico do Maranhão; o Atlas Linguístico do Rio Grande do Norte e o Atlas Linguístico do Piauí.

Outros Atlas em elaboração como teses de doutorado e dissertações de mestrado são: o Atlas Linguistico da Mata Sul de Pernambuco, de Edilene Almeida, como dissertação de mestrado na UFPB; o Atlas Linguístico de Iguatu-CE, de Fabiana dos Santos Lima, como dissertação de mestrado na UFC; e o Atlas Linguístico da Mesorregião do Oeste Potiguar, de Moisés BAtista da Silva, como tese de doutorado na UFC.

Nossa análise, neste trabalho, será feita com itens lexicais dos Atlas Linguísticos da Bahia, Minas Gerais, Paraíba, Sergipe e Paraná.

\subsection{Análise de cartas léxicas}

Para nossa análise trabalhamos com itens lexicais de algumas cartas léxicas dos campos semânticos "fenômenos atmosféricos", "corpo humano" e "cultura e convívio", dos cinco Atlas brasileiros publicados.

\subsubsection{Arco-iris}

O conceito de barras coloridas que aparecem no céu, antes ou depois da chuva, apresentou, nesses Atlas, as seguintes variantes: 
a) $\mathrm{Na}$ Bahia

$\begin{array}{lll}\text { Arco-íris } & \text { Arco } & \text { Arco-celeste } \\ \text { Arco-da-velha } & \text { Arco de velho } & \text { Arco-de-boi } \\ \text { Arco-da-aliança } & \text { Sete-couros } & \text { Barra-de-nuvem }\end{array}$

b) Em Minas Gerais

$\begin{array}{lll}\text { Arco-íris } & \text { Arco-da-velha } & \text { Arco-da-aliança } \\ \text { Arco-do-sol } & \text { Rabo-de-galo } & \text { Olho-de-boi } \\ \text { Mãe-d’água } & \text { Rabo-de-pavão } & \text { Navio }\end{array}$

c) Na Paraíba

$\begin{array}{lll}\text { Arco-íris } & \text { Arco-celeste } & \text { Olho-de-boi } \\ \text { As barras } & \text { Sub-dourada } & \text { As torres } \\ \text { Os véus } & \text { Os vieiras } & \text { Arco }\end{array}$

d) Em Sergipe

$\begin{array}{lll}\text { Arco-íris } & \text { Arco-celeste } & \text { Arco-da-velha } \\ \text { Arco-de-boi } & \text { Arco-de-velho } & \text { Olho-de-boi }\end{array}$

e) No Paraná

Arco-íris Arco-da-aliança Arco-da-velha Arco-de-velho Arco-da-aliança de Jesus

Arco-da-nova-aliança

Aliança de Cristo com os homens

Das vinte e três variantes encontradas para a forma básica, arco-íris, ela foi a única a ocorrer em todas as regiões. Outras formas, como arco-celeste, arco-da-velha, arco-da-aliança e arco-de-velho são comuns a algumas regiões, mas não a todas.

Pode-se observar, neste caso, que o sema genérico comum a quase todos os itens lexicais é a forma de arco como se apresentam 
as barras coloridas que aparecem no céu, antes ou depois da chuva. Dos 40 itens encontrados, 26 têm a forma arco, ou seja, 65\% do total. Alguns semas específicos e os virtuais é que vão marcar as variantes léxicas de arco-íris.

\subsubsection{Estrela cadente}

A questão referente a Estrela Cadente - De noite, muitas vezes pode-se observar uma estrela que se desloca no céu e faz um risco de luz. Como chamam isso? - apresentou as seguintes variantes:

a) $\mathrm{Na}$ Bahia

$\begin{array}{lll}\text { Zelação } & \text { Velação } & \text { Planeta } \\ \text { Cometa } & \text { Estrela corredeira } & \end{array}$

b) Em Minas Gerais

$\begin{array}{lll}\text { Estrela cadente } & \text { Cometa } & \text { Planeta } \\ \text { Papa-ceia } & \text { Diamante } & \text { Zelação } \\ \text { Estrela de rabo } & \text { Satélite } & \text { Mãe-do-ouro }\end{array}$

c) Na Paraíba

$\begin{array}{lll}\text { Estrela cadente } & \begin{array}{l}\text { Estrela d'alva } \\ \text { Zelação }\end{array} & \begin{array}{l}\text { Planeta } \\ \text { Papa-ceia }\end{array} \\ \text { Viração } & \text { Mercúrio } & \text { Barca } \\ \text { Rabisca } & \text { Elevação } & \\ \text { Estrela Mariana } & \text { Deus te abrande } & \\ \text { Estrela se mudando } & & \\ \text { d) No Paraná } & & \\ \text { Mãe-de-ouro } & \text { Planeta } & \text { Estrela de rabo } \\ \text { Satélite } & \text { Cometa } & \text { Estrela da guia }\end{array}$




$\begin{array}{lll}\text { Aparelho } & \text { Diamante } & \text { Rabo de fogo } \\ \text { Estrela do oriente } & \text { Estrela Dalva } & \text { Estrela guia } \\ \text { Estrela corredeira } & \text { Rabo de estrela } & \end{array}$

Num total de vinte e oito itens lexicais que formam as variantes para Estrela Cadente, apenas Planeta é encontrado nos quatro Atlas em que se encontra esta questão. A seguir, em termos de difusão para outras regiões, vem Cometa e Zelação. As demais formas aparecem em duas ou em uma das regiões.

Vê-se que, neste caso, o sema genérico de estrela cadente, planeta e cometa é astro sem luz própria, pois mesmo estrela cadente, que por ser chamada de estrela deveria ser astro luminoso, nas definições de dicionários é "fragmento de matéria do espaço interplanetário que ao penetrar na atmosfera se aquece, tornandose luminoso", ou seja, ele somente adquire luminosidade ao entrar na atmosfera. Do total de 42 ocorrências, 18 têm como sema genérico astro sem luz própria, ou $42 \%$ do total. As demais designações são diferenciadas pelos semas específicos e virtuais, ou são, em alguns casos, variantes fonéticas, que passam a se constituir em um novo item lexical, como no caso de velação e želação.

\subsubsection{Avarento}

A questão referente à pessoa que não gosta de gastar o seu dinheiro e, às vezes, até passa dificuldades para não gastar obteve como resposta as seguintes variantes:

a) Na Bahia

$\begin{array}{lll}\text { Avarento } & \text { Canguinho } & \text { Usurave } \\ \text { Sovino } & \text { Econômico } & \text { Usurento } \\ \text { Morto-de-fome } & \text { Morto-a-fome } & \text { Seguro } \\ \text { Mão-apertada } & \text { Amarrado-por-detrás } & \text { Pão-duro } \\ \text { Pechincheiro } & \text { Agarrado } & \text { Somítico }\end{array}$


b) Na Paraíba

$\begin{array}{llr}\text { Amarrado } & \text { Unha-de-fome } & \text { Pica-fumo } \\ \text { Mesquinho } & \text { Sovina } & \text { Econômico } \\ \text { Chula } & \text { Fona } & \text { Somítico } \\ \text { Seguro } & \text { Fominha } & \text { Arrochado } \\ \text { Morto-a-fome } & \text { Usurário } & \text { Morto-de-fome } \\ \text { Papagaio-no-arame } & \text { Agarrado } & \text { Enforcado } \\ \text { Miserável } & \text { Resina } & \end{array}$

Dominado pelo dinheiro

Amarrado que nem catarro na parede

c) Em Sergipe

$\begin{array}{lll}\text { Pão-duro } & \text { Somítico } & \text { Fona } \\ \text { Seguro } & \text { Casquinha } & \text { Canguinha } \\ \text { Morto-a-fome } & \text { Sovina } & \text { Usurário }\end{array}$

Unha-de-fome

Das trinta e uma variantes lexicais para avarento, apenas sovina(o), somítico, seguro e usurário são comuns às três regiões pesquisadas. As demais formas encontram-se distribuídas de modo irregular entre as regiões.

Neste caso o sema genérico é não gastar dinheiro, já os demais itens lexicais estão relacionados à forma até física como o sovina guarda seu dinheiro, como nos exemplos de mão apertada, unha de fome, agarrado, seguro, arrochado, papagaio no arame, amarrado que nem catarro na parede. Num total de 48 itens lexicais, 12 têm esse sema genérico, $25 \%$ do total. As demais formas encontradas têm semas específicos também comuns, ligados à economia feita pelos sovinas, como, por exemplo, econômico, pão-duro, pecbincheiro, pica-fumo, fominha, mesquinho, dominado pelo dinbeiro.

3.2.4 Útero

A questão referente à parte do corpo da mãe onde fica o 
nenê/bebê antes de nascer obteve como resposta as seguintes variantes:

a) Na Bahia

$\begin{array}{lll}\text { Útero } & \text { Ova } & \text { Mãe do corpo } \\ \text { Saco } & \text { Bacia } & \text { Senhora do corpo } \\ \text { Dona do corpo } & \text { Madre } & \text { Comadre }\end{array}$

b) $\mathrm{Na}$ Paraíba

Útero Ventre Mãe do corpo

Ventre da mãe Bacia

c) Em Sergipe

Útero Companheira Bacia

Fato Saco

d) No Paraná

$\begin{array}{lll}\text { Útero } & \text { Barriga } & \text { Mãe do corpo } \\ \text { Bacia } & \text { Ventre } & \text { Bolsa }\end{array}$

Das quinze variantes lexicais para útero, são comuns às quatro regiões pesquisadas: útero, mãe do corpo, bacia. As demais formas encontram-se distribuídas de modo irregular entre as regiões.

Nas três formas encontradas em todos os estados pesquisados o sema genérico está relacionado ao lugar onde a criança fica antes de nascer; em bacia, a marca é de local do corpo humano onde está o útero e em mãe do corpo há uma denotação de raiz, matriz da vida que se gerou. As outras formas encontradas também mantêm os mesmos semas genéricos de local onde a criança é gerada como em bolsa, fato, saco, ova, ou matriz da vida, que comanda o corpo, como em mãe do corpo, senhora do corpo, dona do corpo, madre. 
Dos 25 itens encontrados, 12 têm o mesmo sema genérico, ou seja, $48 \%$ do total.

\subsubsection{Rótula}

A questão referente ao conceito osso redondo que fica na frente do joelho obteve, nos quatro Atlas que consideraram esta questão, a seguinte variação lexical:

a) $\mathrm{Na}$ Bahia

$\begin{array}{lll}\text { Rótula } & \text { Pataca } & \text { Bolacha } \\ \text { Pataquinha } & \text { Patinho } & \text { Cotovelo } \\ \text { Bolachinha } & \text { Prato } & \text { Rodela } \\ \text { Carapuça } & \text { Bolinha } & \end{array}$

b) Na Paraíba

$\begin{array}{lll}\text { Rótula } & \text { Cabeça do joelho } & \text { Bolacha } \\ \text { Patinho } & \text { Bolacha do joelho } & \text { Bolachinha }\end{array}$

Rodinha do joelho

c) Em Sergipe

$\begin{array}{lll}\begin{array}{l}\text { Rótula } \\ \text { Bola } \\ \text { Cotovelo }\end{array} & \begin{array}{l}\text { Pratinho } \\ \text { Patinho } \\ \text { Carapucinha }\end{array} & \begin{array}{l}\text { Bolacha } \\ \text { Catoca } \\ \text { Cabeça }\end{array} \\ \text { d) No Paraná } & \text { Batata } \\ \begin{array}{l}\text { Rótula } \\ \text { Patacão } \\ \text { Bolacha do joelho }\end{array} & \begin{array}{l}\text { Bolacha } \\ \text { Travela do joelho }\end{array} & \begin{array}{l}\text { Pataca } \\ \text { Travela }\end{array}\end{array}$

Num total de vinte e quatro itens lexicais que formam as variantes para rótula, são encontrados, nos quatro Atlas onde esta 
questão é feita, apenas as formas rótula e bolacha. A seguir, em termos de difusão para outras regiões, vem patinho. As demais formas aparecem em duas ou em uma das regiões.

O sema genérico encontrado foi o de osso redondo articulado. Já os específicos e virtuais estão, do mesmo modo, associados à forma arredondada como, por exemplo, em rodela, bolacha, bolachinha, pataca, rodinha, prato.

De 35 itens encontrados, 20 contêm o sema redondo ou arredondado, ou seja, $57 \%$ do total.

\section{Considerações finais}

Ao nos propormos a trabalhar com as relações de significação dos itens lexicais dos Atlas Linguísticos Regionais do Brasil, partimos do questionamento se esses itens lexicais poderiam ser considerados sinônimos ou, ao contrário, se eles poderiam ser vistos como parassinônimos.

Após a leitura de vários autores das áreas de semântica, semiótica, lexicologia e lexicografia, com diferentes visões sobre o tema, chegamos à conclusão, concordando com esses autores, de que a questão da sinonímia é uma questão de gradação e de variação quer linguística, quer extralinguística, e que não há sinônimo perfeito, uma vez que o semema de nenhum item lexical recobre totalmente o semema de outro item.

Vimos, também, que a sinonímia não pode ser vista apenas como dois itens lexicais que têm o mesmo significado, mas ela deve ser analisada a partir das relações de significação como funções desses itens lexicais.

Respondendo à questão inicial, se os itens lexicais dos Atlas Linguísticos são parassinônimos, estamos seguros que sim, que cada um deles, apesar de terem os mesmos semas genéricos, seus semas específicos e virtuais recobrem realidades geográficas regionais diferentes, que se constituem em subsistemas marcados pela variação diatópica, já que diastraticamente as marcas da variação social, faixa etária, sexo e nível de escolarização têm características semelhantes ou iguais, o que contraria a visão de alguns autores da área. 
Nossa conclusão é, portanto, que os itens lexicais dos Atlas Linguísticos são parassinônimos, sinônimos imperfeitos, quase sinônimos, sinônimos de discurso, pseudossinônimos, ou outros nomes quaisquer que lhes sejam dados.

\section{Referências}

AGUILERA, Vanderci de Andrade. As conquistas do Atlas Lingǘstico do Brasil: um balanço no início do século XXI. In: SILVA, D. E. G. II Encontro Nacional do Grupo de Estudos da Linguagem do Centro-Oeste. Integração linguística, étnica e social. Atas. Brasília: Oficina Editorial do Instituto de Letras da UnB, 2004. v. III. p. 877-843.

(Org.) A geolingüística no Brasil: caminhos e perspectivas. Londrina: EdUEL, 1998.

Atlas lingüístico do Paraná. Apresentação. Londrina: EdUEL, 1996.

. Atlas lingüístico do Paraná. Curitiba: Imprensa Oficial do Estado do Paraná, 1994.

ALMEIDA, Fabiana da Silva Campos. Micro Atlas Fonético do Estado do Rio de Janeiro (Micro AFERJ) - uma contribuição para o conhecimento dos falares fluminenses. 2008. 157p. Tese (Doutorado em Letras Vernáculas) - Universidade Federal do Rio de Janeiro, Rio de Janeiro.

ARAGÃO, Maria do Socorro Silva de; MENEZES, Cleusa P. B. Atlas lingüístico da Paraíba: cartas léxicas e fonéticas. Brasília: CNPq/UFPB, 1984.

BARBOSA, Maria Aparecida. Relações de significação nas unidades lexicais. In: CARVALHO, Nelly Medeiros; SILVA, Maria Emília Barcellos da (Orgs.). Anais do $\mathbf{1}^{\circ}$ Encontro Nacional do GT de 
Lexicologia, Lexicografia e Termiologia da Anpoll. Recife: UFPE/CNPq, (1998). p. 19-20.

CARDOSO, Suzana Alice Marcelino. Atlas lingüístico de Sergipe II. Salvador: EDUFBA, 2005.

CRUSE, D. A. Lexical semantics. Cambridge: Cambridge University Press, 1991.

CRUZ, Maria Luiza da. Atlas lingüístico do Amazonas. 2004. Tese (Doutorado em Letras Vernáulas) - Universidade Federal do Rio de Janeiro, Rio de Janeiro. $2 \mathrm{v}$.

CRYSTAL, David. Dicionário de lingüística e fonética. Rio de Janeiro: Zahar, 1988.

CUBA, Marigilda Antônio. Atlas lingüístico da Mesorregião sudeste de Mato Grosso. 2009. Dissertação (Mestrado em Letras) - Universidade Federal de Mato Grosso do Sul, Campo Grande.

FERREIRA, Carlota da S. et al. Atlas lingüístico de Sergipe. Salvador: Instituto de Letras/Fundação Estadual de Cultura de Sergipe, 1987.

LIMA, Luciana Gomes de. Atlas fonético do entorno da Baia de Guanabara. 2006. Dissertação (Mestrado em Letras) Universidade Federal do Rio de Janeiro, Rio de Janeiro.

LOPES, Edward. Fundamentos da lingüística contemporânea. São Paulo: Cultrix, 1976.

LYONS, John. Semantics. Cambridge: Cambridge University Press, 1988. 1979.

Introdução à lingüística teórica. São Paulo: Nacional, Semântica estrutural. Lisboa: Presença, 1974.

MATTHEWS, Peter. The concise Oxford dictionary of linguistics. Oxford: Oxford University Press, 1997. 
OLIVEIRA, Dercir Pedro de. (Org.). Atlas lingüístico do Mato Grosso do Sul - ALMS. Campo Grande: UFMS, 2007.

PEREIRA, Maria das Neves. Atlas geolingüístico do litoral potiguar. 2007.136p. Tese (Doutorado em Letras) - Universidade Federal do Rio de Janeiro, Rio de Janeiro.

POTTIER, Bernard. Linguistique générale: théorie et description. Paris: Klincksieck, 1974.

RAZKY, Abdelhak. (Org.) Atlas lingüístico sonoro do Pará. Belém: UFPA/CAPES/UTM, 2004. 1 CDRom.

REIS, Regiane Coelho Pereira. Atlas lingüístico do município de Ponta Porã-MS: um registro das línguas em contato na fronteira do Brasil com o Paraguai. 2006. Dissertação (Mestrado em Letras) - Universidade Federal de Mato Grosso do Sul, Três Lagoas.

RIBEIRO, José; Mário Roberto L. Zágari; José Passini; Antonio Pereira Gaio. Esboço de um atlas lingüístico de Minas Gerais. Rio de Janeiro: Fundação Casa de Rui Barbosa, 1977.

ROSSI, Nelson; FERREIRA, Carlota; ISENSEE, Dinah. Atlas prévio dos falares baianos. Rio de Janeiro: INL, 1963.

XAVIER, Maria Francisca; MATEUS, Maria Helena Mira (Orgs.) Dicionário de termos lingüísticos. Lisboa: Cosmos, v. II, 1992. 